\title{
Audiencia social en España: Estrategias de éxito en la televisión nacional
}

\section{Social Audience in Spain: Succesful strategies in national TV}

\author{
Marta Saavedra Llamas \\ Prof. y Coordinadora de Calidad en la Facultad de \\ Ciencias de la Comunicación \\ (Universidad Nebrija) \\ Leticia Rodríguez Fernández \\ Profesora Asociada en la Facultad de Ciencias de la Comunicación \\ (Universidad Nebrija) \\ Gemma Barón Dulce \\ Coordinadora Académica del Máster Universitario en \\ Dirección de Publicidad Integrada TBWA \\ (Universidad Nebrija)
}

Fecha de recepción: 25 de marzo de 2015

Fecha de revisión: 14 de junio de 2015

Para citar este artículo: Saavedra Llamas, M., Rodríguez Fernández, L. y

Barón Dulce, G. (2015): Audiencia social en España: Estrategias de éxito en la televisión nacional, Icono 14, volumen (13), pp. 215-237. doi: 10.7195/ ri14.v13i2.822 


\section{Resumen}

El presente trabajo de investigación aborda el concepto de audiencia social, nuevo espacio narrativo nacido de la convergencia de la audiencia televisiva y las conversaciones de usuarios en Twitter, analizando las estrategias de los programas de la televisión española con mayor impacto social. Entender qué es exactamente la audiencia social, cómo funciona o qué tipo de mediciones se realizan de la misma se hace más necesario que nunca para ahondar en los usos y oportunidades que supone tanto para el medio televisivo como para los anunciantes, que deciden invertir en un espacio determinado. A través del estudio de casos exitosos ya implantados se pretende establecer fórmulas de éxito que logren una participación aún más activa de los usuarios, el trasvase de audiencia social a la audiencia tradicional y la inclusión ventajosa de las marcas en este nuevo escenario comunicacional cargado de posibilidades.

Palabras clave: Audiencia social - Estrategias digitales - Twitter - Transmedia Gran Hermano - La Sexta Noche - Quién quiere casarse con mi hijo

\section{Abstract}

This research presents the concept of social audience, as a new narrative space born in the convergence of the TV audience and the user's conversations in Twitter, and examine strategies of TV programs in Spain with higher social audience. Understand what exactly the social audience is, how does it works or what kind of metrics are made for it, becomes more necessary than ever to deepen into the uses and opportunities facing both the television media and advertisers who choose to invest in a TV space.Through the study of successful cases already implemented is to establish formulas for success that achieve a more active participation of users, transfer from social to traditional audience and the profitable inclusion of brands in this full of possibilities new communication scenario.

Key Words: Social audience - Digital strategies - Twitter - Transmedia - Gran Hermano - La Sexta Noche - Quién quiere casarse con mi hijo

ICONO14 | Año 2015 Volumen 13 № 2 | ISSN: 1697-8293 | DOI: ri14.v13i2.822 


\section{Introducción}

La hegemonía de la televisión como medio, sumada a los procesos de digitalización y a un mayor acceso a la tecnología y a la doble pantalla han dado lugar a un nuevo tipo de audiencia, la derivada de los comentarios que se producen diariamente en redes sociales: la audiencia social. Ahora, el espectador-consumidor opina sobre la programación televisiva, influye en ella y manifiesta abiertamente sus preferencias sobre los contenidos y marcas que aparecen en dichos formatos.

La audiencia actual se caracteriza, según Quintas-Froufe y González-Neira (2014), por una conexión a la red permanente, universal y dinámica; se trata de una audiencia que participa activamente en el devenir de la propia programación y que demanda un intercambio vertical y bidireccional de información entre el emisor tradicional o programa de televisión y el receptor y no sólo una interacción horizontal con otros usuarios.

Con la implantación de la televisión social, el consumo del usuario pasa de ser lineal a ser experiencial y la actitud pasiva del espectador se convierte en una relación de engagement (compromiso) con el medio.

La red social que protagoniza la conversación sobre la televisión es Twitter y, según distintos expertos como Castelló (2013), Rodríguez Breijo y Pestano (2013) o Orihuela (2011), el motivo es su fácil uso, que permite el comentario en tiempo real respecto al visionado, fomenta la interacción con otros usuarios y con el propio programa y sus protagonistas (presentadores, concursantes, actores, directores, cadena, marcas patrocinadoras...) y facilita el comentario en un espacio idóneo a través de los hashtags (etiquetas) creados de manera oficial o por los propios usuarios.

La televisión social permite el impulso de la participación del usuario gracias a la medición de esa interacción que contribuye a conocer con mayor precisión el perfil de audiencia de cada formato televisivo. En el mercado nacional, este trabajo ha sido asumido en una fase temprana por Global in Media y Tuitele, adquirida en abril de 2014 por el grupo Kantar Media. Esta empresa actualmente coordina y dirige la medición directamente con Twitter a través de KantarTwitter TV Ratings, la primera medición oficial de audiencia en esta red social.

DOI: ri14.v13i2.822 | ISSN: 1697-8293 | Año 2015 Volumen 13 № 2 | ICONO14 
Kantar Media ofrece datos como los tuits (tweets) totales enviados sobre una emisión, los picos de mayor número de mensajes, el número de usuarios que ha leído esos tuits o las visualizaciones de un comentario. Por otra parte, Global in Media localiza términos de búsqueda, en este caso relacionados con un programa de televisión, en distintas redes sociales como Twitter, Facebook, Youtube, MySpace y blog con RSS.

La medición de la audiencia social supone un salto cualitativo ya que hasta el momento la planificación de la programación televisiva y su éxito habían estado directamente relacionados con los datos expresados por la audiencia tradicional (Saavedra, Rodríguez y Perlado, 2015). Entre sus beneficios encontramos:

- La audimetría social aporta una valoración cualitativa de los comentarios generados, ofrece los sentimientos de la audiencia, y permite discernir entre opiniones positivas o negativas respecto a contenidos y marcas.

- Mejora el cocimiento de la audiencia, sus intereses y apreciaciones sobre el programa televisivo y esta información puede ayudar a implementar estrategias de fidelización de la audiencia por parte de las cadenas de televisión, ofreciendo además targets más definidos a los anunciantes.

- La audiencia social y tradicional pueden correlacionarse. Las cadenas pueden implementar fórmulas para trasvasar seguidores sociales a la audiencia tradicional. Consultoras como Nielsen (2013) han demostrado que existe una relación directa entre el aumento de comentarios sobre un programa y el crecimiento de espectadores tradicionales. En esta línea, el director general de Twitter en España, Pepe López de Ayala, sostiene que el 67\% de los usuarios de la red social reconoce visionar un programa por los comentarios leídos. Por otro lado, si observamos el impacto de estos medios de comunicación -televisión e Internet- según la edad de los usuarios y a partir del EGM, descubrimos que si la televisión tiene sus mayores cotas de participación en el segmento de 35 a más de 65 años, Internet lo tiene en el segmento de 14 a 34 años. Ambos medios se pueden complementar para alcanzar a más población y fomentar el consumo de uno a través del otro.

ICONO14 | Año 2015 Volumen 13 Nº 2 | ISSN: 1697-8293 | DOI: ri14.v13i2.822 
- La audiencia social aporta interesantes oportunidades para los anunciantes y marcas si activan su interrelación con los usuarios y gestionan socialmente su participación en programas televisivos, incrementando los beneficios obtenidos por su inversión en el medio. Este nuevo escenario publicitario coincide, además, con el aumento de la actividad en redes sociales por parte de las marcas. Según el l Estudio Top 50 Marcas en Redes Sociales de IAB (2015), las marcas incrementaron por cinco su actividad en redes sociales durante 2014.

Ante este nuevo escenario, Arrojo (2013) indica cinco retos en relación a la audiencia social que deben marcarse las televisiones: aumentar la audiencia social, atraer a más espectadores y mejorar la audiencia tradicional, obtener más conocimientos sobre la opinión de la audiencia, contribuir a aumentar el fenómeno fan sobre un contenido y ofrecer un producto más atractivo para captar mayores ingresos por publicidad. Un sexto reto sería aumentar el tráfico de visitantes en las webs de las cadenas y mejorar así tanto este submedio como a los productos filiales alojados en él y el rendimiento de los espacios publicitarios (Saavedra, Rodríguez, Perlado, 2015).

Próximamente, televisiones y anunciantes tendrán que hacer frente a un séptimo reto: adaptar sus estrategias a las nuevos timelines (cronologías) para televisión que prepara Twitter. La red social ya ha manifestado su intención de lanzar timelines especializados en el medio televisivo para su versión móvil, que permitirían agrupar más fácilmente la conversación en torno a un programa.

Este esfuerzo de la red social por adaptarse a la audiencia social, desarrollando tecnología específica, alimenta la necesidad de conocer cuál es el escenario actual de la audiencia social en España y de analizar cómo son las estrategias de televisiones y anunciantes en este ámbito.

\section{Método de la investigación}

El principal objetivo de esta investigación es analizar estrategias de comunicación social exitosas desarrolladas por programas de la televisión nacional con la intención de obtener unas pautas victoriosas que logren aumentar el impacto social del espacio y ampliar el número de seguidores.

DOI: ri14.v13i2.822 | ISSN: 1697-8293 | Año 2015 Volumen 13 Nº 2 | ICONO14 
Como objetivo secundario, se tratará de valorar la participación del medio televisivo y de los anunciantes en la conversación social subrayando retos y oportunidades de este nuevo escenario comunicativo.

Para el desarrollo de la investigación, realizamos en primer lugar un estudio descriptivo basado en fuentes secundarias sobre el concepto de audiencia social, su evolución y sistemas de medición.

En la segunda parte del estudio, hemos procedido al análisis de una serie de programas de televisión a partir de la siguiente matriz:

\begin{tabular}{|c|c|c|c|c|c|}
\hline \multicolumn{6}{|c|}{ FICHA TÉCNICA DEL PROGRAMA } \\
\hline $\begin{array}{l}\text { Nombre del } \\
\text { programa }\end{array}$ & Canal & $\begin{array}{l}\text { Fecha de } \\
\text { emisión }\end{array}$ & \multicolumn{2}{|c|}{$\begin{array}{c}\text { Franja horaria } \\
\text { de emisión }\end{array}$} & $\begin{array}{c}\text { Estilo y género } \\
\text { del programa }\end{array}$ \\
\hline \multicolumn{2}{|c|}{$\begin{array}{l}\text { INTERACCIÓN } \\
\text { DEL PROGRAMA }\end{array}$} & \multicolumn{2}{|c|}{$\begin{array}{l}\text { INTERACCIÓN } \\
\text { DEL USUARIO }\end{array}$} & & $\begin{array}{l}\text { INTERACCIÓN } \\
\text { PUBLICITARIA }\end{array}$ \\
\hline \multicolumn{2}{|c|}{$\begin{array}{l}\text { Cuenta oficial en Twitter } \\
\text { (nombre y actividad). } \\
\text { Actividad en las cuentas } \\
\text { de los emisores. } \\
\text { Utilización de hashtags } \\
\text { propios durante la emisión } \\
\text { (tipo, ubicación en panta- } \\
\text { lla, trayectoria de la eti- } \\
\text { queta, fomento de su uso } \\
\text { por parte del programa). } \\
\text { Seguimiento de la audien- } \\
\text { cia social durante la emi- } \\
\text { sión (reflejo de la partici- } \\
\text { pación de los usuarios). } \\
\text { Disponibilidad de aplica- } \\
\text { ción móvil (tipo, vínculo } \\
\text { con la conversación social, } \\
\text { fomento de su uso durante } \\
\text { la emisión, reflejo de la } \\
\text { participación durante la } \\
\text { emisión). }\end{array}$} & \multicolumn{2}{|c|}{$\begin{array}{l}\text { - Utilización por parte de } \\
\text { los usuarios de los hashtag } \\
\text { sugeridos. } \\
\text { Generación de hashtag } \\
\text { propios (tipo, trayectoria } \\
\text { de la etiqueta) } \\
\text { - } \quad \text { Total de comentarios. } \\
\text { - } \quad \text { Número de usuarios únicos. } \\
\text { - Sentimientos generados. } \\
\text { - Sexo de la audiencia } \\
\text { social. } \\
\text { Comparativa entre la au- } \\
\text { diencia social registrada y } \\
\text { la audiencia tradicional. }\end{array}$} & \multicolumn{2}{|c|}{$\begin{array}{l}\text { Patrocinador del espacio } \\
\text { (disponibilidad de cuenta } \\
\text { oficial en Twitter, parti- } \\
\text { cipación en la conversa- } \\
\text { ción social, contenido de } \\
\text { los mensajes generados, } \\
\text { inclusión de enlaces, uso } \\
\text { del hashtag sugerido por } \\
\text { el programa, inclusión } \\
\text { de promociones en la } \\
\text { conversación social, tuits } \\
\text { patrocinados) } \\
\text { Observación de los } \\
\text { anunciantes que aparecen } \\
\text { identificados dentro de } \\
\text { la emisión (participación } \\
\text { social). } \\
\text { Observación resto de anun- } \\
\text { ciantes. }\end{array}$} \\
\hline
\end{tabular}

Tabla 1: Muestra de análisis programación. Elaboración propia. 
Los datos relacionados con la interacción del usuario han sido recogidos el día posterior a la emisión de cada uno de los espacios y a partir de la información presentada por Global in Media en el portal PR Noticias.

La selección de la muestra de análisis ha sido realizada a partir de los datos de audiencia social del mes de enero de 2015, facilitados por Kantar Media:

\begin{tabular}{|c|c|c|c|c|}
\hline CANAL & PROGRAMA & TUITS & $\begin{array}{c}\text { AUTORES } \\
\text { ÚNICOS }\end{array}$ & SHARE SOCIAL \\
\hline MULTICADENA & $\begin{array}{c}\text { GALA FINAL FIFA } \\
\text { BALON DE ORO }\end{array}$ & 451151 & 145988 & 84.0 \\
\hline T5 & GH VIP & 291750 & 100829 & 68.8 \\
\hline T5 & GH VIP & 232259 & 55114 & 55.3 \\
\hline T5 & GH VIP & 227430 & 66406 & 70.8 \\
\hline LA SEXTA & LA SEXTA NOCHE & 171932 & 36715 & 77.3 \\
\hline T5 & GH VIP & 151718 & 33130 & 50.1 \\
\hline T5 & GH VIP:EL DEBATE & 146589 & 31101 & 49.7 \\
\hline T5 & GH VIP:EL DEBATE & 117624 & 34757 & 53.6 \\
\hline CUATRO & ¿QUIÉN QUIERE CASARSE & 112301 & 34110 & 53.5 \\
\hline
\end{tabular}

Tabla 2: Ranking audiencia social de enero de 2015. Kantar Media.

A partir de este ranking, se procedió a la elección de la muestra atendiendo al siguiente factor: que el programa tuviera una continuación en el mes de febrero de 2015, periodo seleccionado para el análisis de las estrategias de comunicación social desarrolladas. Los datos de Kantar Media del mes de enero se publicaron la primera semana de febrero por lo que la investigación de campo se inició el lunes 9 y se prolongó hasta el sábado 28 de febrero.

Los programas sometidos a análisis son los que se presentan a continuación. Cabe apuntar que, al tratarse de emisiones semanales, se han analizado entre dos y tres capítulos de cada formato:

- Gran Hermano VIP (Telecinco, Grupo Mediaset ,prime time, horario de máxima audiencia del jueves). Emisiones del 12, 19 y 26 de febrero. 
- La Sexta Noche (La Sexta, Grupo Atresmedia, prime time del sábado). Emisiones del 14, 21 y 28 de febrero.

- Gran Hermano VIP: El Debate (Telecinco, Grupo Mediaset, prime time del domingo). Emisiones del 15 y 22 de febrero.

- ¿Quién quiere casarse con mi hijo? (Cuatro, Grupo Mediaset, prime time del miércoles). Emisiones del 11, 18 y 25 de febrero.

\section{Resultados del análisis}

A continuación se muestran los resultados obtenidos tras la investigación realizada en cada formato televisivo. Para facilitar la lectura de los mismos se ha establecido un formato ficha que permita extraer la información de una manera rápida y eficiente.

\subsection{Gran Hermano VIP y Gran Hermano VIP El Debate o el tán- dem perfecto entre audiencia social y tradicional}

Descripción del programa: Gran Hermano VIP (GH VIP) es uno de los realities de Telecinco, se emite cada jueves en prime time (entre las 21:50 y la 01:00 horas, aproximadamente). Su hermano, Gran Hermano VIP. El Debate, se emite cada domingo también en prime time (entre las 22:00 y las 02:00 horas, aproximadamente) y tiene como foco el mismo contenido que las galas de los jueves, razón por la que se analizan conjuntamente.

Ambos realities son líderes de audiencia tradicional y social y cuentan actualmente con un comunidad de seguidores fidelizada que ha contribuido a convertir al programa, diez años después de su primera emisión, en uno de los formatos de ocio y entretenimiento más populares de la parrilla televisiva. Emitidos íntegramente en directo, la diferencia entre ambos programas reside en la presentación del contenido televisivo: mientras que en Gran Hermano VIP las galas se centran en la participación de los concursantes a lo largo de la semana, El Debate entrevista 
al último concursante expulsado y cuenta con tertulianos procedentes de distintos ámbitos. El presentador de ambos espacios es Jordi González.

Estrategia de audiencia social del programa: La estrategia en redes sociales es común para ambos programas y se desarrolla a través de dos cuentas oficiales de Twitter: @ghmomentazos, enlazada desde la página web de Telecinco,y @ GHoficial, la cuenta propia de Gran Hermano que se ha adaptado en este caso al formato VIP. Las dos cuentas trabajan de manera similar: priorizan el contenido propio y su actualización es diaria, aunque los jueves y domingos, durante la emisión de las galas y debates, se registra mayor actividad, concentrada fundamentalmente antes y durante la emisión.

Sus tuits destacan las últimas informaciones del concurso, los comentarios más polémicos de los tertulianos, comparten imágenes de los directos y buscan medir en algunos casos la opinión pública incentivando en los usuarios el retuit y los favoritos, táctica que además contribuye en la viralización social.

Ambas cuentas participan incluyendo en algunos de sus tuits el hashtag oficial, creado siempre a partir del nombre y número del programa (\#DBT5GHVIP, \#DBT6GHVIP o \#Gala6GhVIP, \#Gala7GhVIP, \#Gala8GhVIP) y que se sobreimpresiona durante la emisión, de manera permanente, en la esquina superior izquierda de la pantalla. Gracias a esta secuencia, la audiencia social genera comentarios antes del inicio del programa, convirtiendo el hashtag oficial en trending topic (asuntos más comentados) en España pocos minutos después de comenzar su retransmisión. Este comportamiento se repite cada jueves y domingo $\mathrm{y}$, en algunos casos, el trending topic se mantiene activo al día siguiente.

Durante las emisiones, la cuenta de la cadena (@Telecinco) registra una actividad reducida.

El papel de los colaboradores/ presentadores: Es importante señalar que los tertulianos, colaboradores y ex concursantes del programa suelen participar tanto de los hashtags oficiales como de los generados por los usuarios, comentando el formato en directo. En consecuencia, su trabajo en redes sociales resulta especialmente

DOI: ri14.v13i2.822 | ISSN: 1697-8293 | Año 2015 Volumen 13 № 2 | ICONO14 
atractivo para el programa, cuyas cuentas oficiales suelen mencionarlos frecuentemente en sus conversaciones para mejorar la interacción e incentivar la participación social. Los tertulianos participan en otros programas de la cadena o son referencia en el mundo del entretenimiento, presentando un gran número de seguidores en sus cuentas de Twitter. Es el caso de Kiko Hernández (@Kiko_Hernandez) con más de medio millón de followers(seguidores), Nagore Robles (@Nagore_Robles) con más de 300.000 o Carmen Alcayde (@carmenalcayde) con 250.000. Sin embargo, este trabajo no se refleja en pantalla, ya que en la sobreimpresión de los nombres de los tertulianos no se incluyen sus cuentas de Twitter, ni siquiera en el caso del presentador (@jordiGlez), que cuenta actualmente con más de 10.000 followers.

Tipo de interacción social: Los usuarios se muestran muy activos en la conversación social, generalmente empujados por los clubs de fans, los tertulianos y la inclusión de contenidos del reality en otros programas de la cadena. Prueba de ello es la generación constante de hashtags propios, al margen del oficial, y la continuidad de los mismos días después de la emisión del programa. Junto al hashtag oficial se van sumando los generados por los usuarios, muchos de los cuáles terminan convirtiéndose también en trending topics. Es el caso de la primera gala analizada (\#Gala6GhVIP), en la que los usuarios llegaron a colocar 12 hashtags entre los trending topics nacionales durante las cuatro horas de emisión del programa. Algunos tuvieron un posicionamiento casi fugaz, mientras que otros convivieron durante varios minutos con la etiqueta oficial. Generalmente y dado el carácter de los hashtags generados por los usuarios (a veces un poco ofensivos o tendenciosos hacia los concursantes), las cuentas oficiales de ambos programas se mantienen al margen de estas conversaciones.

El programa no refleja la participación de la audiencia social; a pesar de ser líderes en este campo, el reality no aprovecha al 100\% su éxito en Twitter. Las alusiones a la conversación social son mínimas y suelen estar relacionadas con comentarios realizados por el presentador o los tertulianos. En ningún caso se anima directamente a los usuarios a comentar el programa. En la gala del 12 de febrero, se comunicó al final del programa los resultados del concurso \#TeAmoGHVIP, desarrollado desde las cuentas oficiales pero que en ningún momento de la retransmisión contó con impulso a su participación.

ICONO14 | Año 2015 Volumen 13 Nº 2 | ISSN: 1697-8293 | DOI: ri14.v13i2.822 
Anunciantes del formato y audiencia social: La audiencia social tampoco es aprovechada publicitariamente. En los cinco programas analizados, solo se identifican dos anunciantes, ambos en el formato de gala de Gran Hermano VIP. El primero, Telepizza, ofreció una cena a los concursantes del reality durante la semana de San Valentín; acción que se vio reflejada durante la gala emitida el 12 de febrero, reforzada además por otros programas de la cadena como Sálvame o El resumen de Gran Hermano VIP, que durante los días posteriores emitieron, en distintas franjas horarias, las imágenes de la inserción. Pese a la claridad y repetición de la acción publicitaria, la marca no realizó ningún tipo de comentario en su cuenta oficial (@ telepizza_es) durante la emisión de la gala. Tampoco ofreció ninguna clase de incentivo o promoción a sus seguidores. Las cuentas oficiales del programa tampoco participaron en la acción publicitaria.

El segundo anunciante identificado, Job and Talent, utilizó una telepromoción antes de un corte publicitario, durante la gala emitida el 26 de febrero, para promocionar su aplicación móvil. Al igual que el anunciante anterior, la planificación publicitaria se limitó a la telepromoción y no se realizó ningún comentario en su cuenta (@jobandtalent_es), ni se incentivó ninguna acción promocional.

La carencia de una estrategia integrada en los grandes anunciantes que englobe la audiencia social llama la atención al comprobar que ambos programas ofrecen los mejores ratings publicitarios. Tomando como referencia los datos de OMD, en las dos primeras semanas de análisis ambos espacios dieron el spot de oro de la semana a la última campaña de Canal+ con 12,5 Grp's, mientras que la última semana ofreció el segundo a la película Kingsman: Servicio secreto, con 10,8 Grp's.

Contrariamente, las pequeñas marcas se muestran mucho más activas en la conversación social, utilizando Twitter como un valioso escaparate para dar a conocer sus productos. Es el caso de Rojo Carmesí (@ROJOCARMESI_ES), firma de moda dedicada la comercialización de vestidos de gala. Durante la emisión de El Debate del día 22 de febrero, una de las tertulianas comentó su estilismo y la firma rápidamente se incluyó en la conversación social aprovechando el espacio promocional. Este patrón se repitió con otras marcas como Stella Blasi’s (@stellablasis). 
Por su parte, Telecinco es plenamente consciente del liderazgo de ambos espacios en audiencia social y tradicional y aprovecha los mismos para promocionar sus propios contenidos televisivos y La Tienda de Gran Hermano VIP, cuya publicidad aparece sobreimpresionada en pantalla con frecuencia, al igual que la aplicación móvil, la gran protagonista de este formato.

Aplicación móvil: Telecinco ha encontrado una nueva vía para incentivar la participación de los usuarios teniendo en cuenta las segundas pantallas. La aplicación, gratuita y disponible para smarthphones, tablets e iphones, presenta un uso sencillo, vinculado a las redes sociales Twitter y Facebook, ya que para poder utilizarla el usuario debe logarse con alguna de las dos redes. A través de esta aplicación, la audiencia puede participar en el contenido social (generalmente encuestas), ver las galas en directo 0 acceder a determinados contenidos alojados en la página web. El uso de la aplicación sí se incentiva de manera continua, ya sea sobreimpresionando información de las votaciones o de la aplicación durante la emisión del programa, a través de menciones del presentador o en las redes sociales.

Resultados audiencia social: Tomando como referencia los datos de Global in Media, durante las cinco emisiones analizadas se alcanza una media de 323.836 comentarios por programa (377.570 comentarios de media en Gran Hermano VIP y 213.235 comentarios de media en $E l$ Debate). La gala número ocho, emitida el 26 de febrero, fue el programa más comentado de 2015.

El número de usuarios únicos oscila entre los 50.000 y los 80.000 en el caso de las galas de los jueves y entre los 35.000 y los 42.000 en el caso de los debates de los domingos. En este sentido, los usuarios se reparten equitativamente entre ambos sexos, generalmente con porcentajes entre el $55 \mathrm{y}$ el $60 \%$ para las mujeres. Predominan los sentimientos negativos frente a los positivos, dato que podría relacionarse directamente con la temática de las galas en las que se generan bandos para buscar la expulsión de alguno de los concursantes.

ICONO14 | Año 2015 Volumen 13 Nº 2 | ISSN: 1697-8293 | DOI: ri14.v13i2.822 


\subsection{La Sexta Noche o cómo el debate político con tertulianos me- diáticos llega a la Red}

Descripción del programa: La Sexta Noche (LSN) es un programa informativo que se emite los sábados en prime time (entre las 21:00 y las 02:00 horas) y en directo. El programa lo presenta Iñaki López, acompañado de Andrea Ropero como copresentadora. La Sexta, perteneciente al Grupo Atresmedia, mantiene este programa desde 2013.

El programa no ha sido líder de audiencia tradicional en todas las emisiones estudiadas, tan solo en uno de los programas, el del 28 de febrero con un 13,5\% de share. En el resto de capítulos se conformó con el tercer puesto y un 10,2\% de cuota de pantalla. En audiencia social, La Sexta Noche ha sido líder en su franja de emisión, obteniendo el 14 de febrero 55.576 comentarios; el 21, 95.362 y el 28, 69.165. La media se sitúa en 73.367 comentarios.

Estrategia de audiencia social del programa: La Sexta Noche presenta una cuenta oficial @SextaNocheTV cuyos comentarios son a menudo retuiteados por la cuenta oficial de la cadena @lasextatv. Su estrategia en redes sociales consiste en adelantar algunos contenidos de la noche antes de la emisión desde la cuenta del programa $\mathrm{y}$, una vez que empieza, sobreimpresionalas cuentas oficiales de los colaboradores al lado del nombre. El programa establece distintos hashtags a lo largo de toda la emisión, sobreimpresionados en la esquina superior izquierda de la pantalla y segmentados según el tipo de contenido. Durante las emisiones, la cuenta del programa tiene una actividad importante en la que destacan los comentarios de los colaboradores o pequeños titulares. Dicha actividad se ve reducida hasta la siguiente emisión. Las cuentas oficiales del programa se muestran imparciales, evitando las polémicas generadas.

El papel de los colaboradores/ presentadores: Las cuentas oficiales de los presentadores presentan actividad antes y después de la emisión y sus comentarios son imparciales e informativos. Por su parte, los colaboradores no tienen ninguna actividad durante la emisión. Habitualmente, periodistas y colaboradores como Paco Marhuenda, Pilar Rahola, Eduardo Inda, Hilario Pino o Ada Colau dan pie con 
sus comentarios, intervenciones y críticas a avalanchas de comentarios en Twitter, llegando alcanzar 95.362 comentarios con 21.572 autores únicos en el programa del 21 de febrero, en el que se trataban temas como las cuentas de Monedero, las tarjetas black de Caja Madrid y la vivienda de Bárcenas en Baqueira. En esta ocasión, los espectadores colocaron además un hashtag propio como trending topic: \#L6Nlíomonedero.

En los otros dos programas, los espectadores han estado más comedidos, alcanzando el 14 de febrero 55.576 comentarios con 14.741 autores únicos y el 28 de febrero 69.165 comentarios con 19.563 autores únicos.

Tipo de interacción social: los espectadores participan activamente con los hashtags que se establecen para cada sección o contenido del programa. El hecho de que los colaboradores sean especialmente mediáticos hace que la actividad social sea mayor, ya que gran parte de los comentarios se dirigen a criticar o apoyar a los mismos. Los comentarios de los colaboradores en plató se retuitean y se comentan con fervor en redes sociales.

Los trending topics que se alcanzaron durante la emisión de estos programas fueron dos el 14 de febrero \#L6Ncrisispsoe y \#L6Nlíomonedero, este último colocado por los usuarios; el 21 de febrero se alcanzaron otros dos, \#L6Nbárcenasbaqueira y \#L6Npapelesmonedero, y el 28 de febrero fueron tres: \#L6Nrosadíez, \#L6Npizarrarallo y \#L6Nsabina.

Anunciantes del formato y audiencia social: Solo se registran marcas comerciales patrocinadoras en los créditos o agradecimientos. Ninguna de ellas presenta una estrategia social definida. Ni siquiera se ha registrado actividad especial 0 relacionada directamente con La Sexta Noche o sus protagonistas en sus cuentas oficiales de Twitter. Las marcas que aparecen regularmente en los créditos son Jack \& Jones (@JackandJonesTM), WESC (@WeSC1999), El Ganso (@elgansospain),Riverside (@RiversideSpain), aCollection y elarmariodelatele.com (@armariodelatele). Como hemos apuntado, ninguna mostró actividad social relacionada con el programa, a pesar de poder haber aprovechado este espacio promocionalmente. Tampoco Edding, marca que apareció en los agradecimientos del 14 de febrero;

ICONO14 | Año 2015 Volumen 13 Nº 2 | ISSN: 1697-8293 | DOI: ri14.v13i2.822 
de hecho, su cuenta internacional (@edding) está en alemán y no hace alusión a España en ningún momento.

Resultados audiencia social: Ninguno de los programas alcanzó el minuto de oro de Twitter en las emisiones generadas. Los comentarios registrados fueron en un 50\% positivos y en un $50 \%$ negativos y el perfil de la audiencia fue mayoritariamente masculino. Como se ha explicado, según los datos de Global In Media, el número medio de comentarios generados fue de 73.367 y la media de usuarios únicos se situó en 18.616.

\section{3. ¿Quién quiere casarse con mi hijo?, una estrategia social de remolque}

Descripción del programa: ¿Quién quiere casarse con mi hijo? (QQCCMH) se ha emitido cada miércoles en prime time (de 22:40 a 00:50 horas, aproximadamente) en la cadena Cuatro, perteneciente a Mediaset. El docu-reality está producido por Eyeworks Cuatro Cabezas y fue estrenado el 30 de enero de 2012; en 2015 se emite la cuarta temporada, que fue estrenada el 13 de enero. Se trata de la adaptación del formato Who wants to marry my son?, que ha sido versionado en Noruega, Bélgica, Holanda, Alemania, Argentina y Francia. Presentado por Luján Arguelles desde su primera entrega, es uno de los programas más comentados en redes sociales.

Estrategia de audiencia social del programa: El fenómeno arrancó ya en la primera temporada $\mathrm{y}$, a los diez minutos del inicio de la primera emisión, el formato se convirtió en el contenido más comentado en Twitter, posicionando diferentes hashtag tanto en el ranking nacional como en el mundial. Las redes sociales fueron utilizadas desde entonces por la cadena como un remolque de la audiencia, trasvasando seguidores sociales a la medición tradicional. Si el programa arrancó con un $10 \%$ de share, las últimas emisiones lograron mantener un $12 \%$ de media. Esta estrategia en redes sociales se mantiene en la actualidad.

Es importante reseñar que el programa cuenta con una cuenta oficial (@ qqccmh), que no solo está activa durante la emisión del programa, sino que muestra continuidad desde el estreno del formato en 2012. Obviamente, los picos de mayor actividad se presentan durante la emisión de las temporadas y en especial

DOI: ri14.v13i2.822 | ISSN: 1697-8293 | Año 2015 Volumen 13 Nº 2 | ICONO14 
desde 30 minutos antes del arranque hasta el final. Antes de la emisión, los mensajes emitidos promocionan la nueva entrega y buscan ampliar el visionado; durante la emisión, resaltan el contenido más destacado $\mathrm{y}$, cuando el programa finaliza, analizan el resultado y publicitan el siguiente capítulo.

La cuenta de la cadena (@cuatro) presenta una tímida actividad; sólo incluye de media dos comentarios por programa emitido. Participan otras cuentas oficiales de la cadena pero no de manera acusada como, por ejemplo, el perfil de Gran HermanoVIP (@ghoficial)y de Hable con ellas (@hableconellast5). La cuenta de la productora (@Eyeworksespana)no presenta actividad.

El programa utiliza un hashtag propio durante la emisión, que sobreimpresiona en pantalla aunque no durante todo el tiempo. Figura en la parte inferior izquierda. Las siglas del programa se acompañan con el número de emisión; los días analizados han coincidido con los hashtag \#QQCCMH5, \#QQCCMH6 у \#QQCCMH7. Lograron posicionarse como trending topic a los 20 minutos de media del arranque del programa, aunque cabe indicar que en el caso del programa número siete, emitido el 25 de febrero de 2015, el hashtag ya se situó en el ranking antes del inicio del espacio (a las 22:25 horas), siendo trending topic mundial a las 22:57 horas. El hashtag se mantiene en el listado de tendencias al día siguiente de la emisión.

El programa no fomenta la participación en redes sociales desde la emisión; al ser un contenido emitido en diferido no incluye una sección que comente los datos registrados en la conversación social.

El papel de los colaboradores/ presentadores: La presentadora del espacio (@ LUJAN_AR) se muestra activa durante la emisión pero sin una participación destacada. Igualmente, las numerosas cuentas de los concursantes de la edición presentan una participación muy acusada y gran volumen de retuits y comentarios. Cabe apuntar que la cuenta oficial de la presentadora se sobreimpresiona en pantalla al inicio del programa, en la presentación del mismo. Consideramos que el pilar de la estrategia se sustenta en el elevado número de emisores oficiales, ya que programa, presentadora y participantes (cinco madres, cinco hijos y 25 candidatos) participan en la conversación social.

ICONO14 | Año 2015 Volumen 13 Nº 2 | ISSN: 1697-8293 | DOI: ri14.v13i2.822 
Tipo de interacción social: Los seguidores siguen el hashtag principal pero también generan otros que logran buenas posiciones en el catálogo de temas más comentados, llegando a ser trending topic, aunque de duración variable. En el primer programa analizado -11 de febrero-se incluyeron en el ranking tres etiquetas en relación a participantes del reality y convivieron otras de menor incidencia. La etiqueta (\#Markus) se mantuvo hasta 12 horas después de la finalización del programa. En el segundo programa observado -18 de febrero- hubo hasta cuatro trendingtopic generados por usuarios (\#María Luisa y \#Christopher, los más longevos). El tercer día -25 de febrero-, los temas generados se multiplican y hasta seis hashtag entran como trending topic; todos tienen una presencia muy fugaz en el ranking.

Anunciantes del formato y audiencia social: Por parte de los anunciantes presentes en el espacio, debemos advertir que no se localiza interacción en la escena social. Cada programa cuenta con tres bloques publicitarios y aunque la mayoría de marcas anunciadas cuenta con perfil social no se observa una participación de las mismas en el contenido social generado por el programa. Especial mención merece el caso de Telepizza, patrocinador del espacio en la primera emisión analizada. Dispone de una cuenta oficial en Twitter (@telepizza_es) pero no participa en la conversación social que rodea al programa a pesar de presentar una campaña fácilmente vinculable al contenido del espacio patrocinado, el lanzamiento de una gama de productos enfocada en la celebración de San Valentín.

El programa cuenta, además, con un espacio recomendado. Se trata de la mención a la firma Único, realizada por Luján Arguelles. Se sobreimpresiona en pantalla la web de la compañía y sus cuentas de Facebook y Twitter pero no se localiza participación en la conversación social por parte de la firma. Podemos mencionar, además, que la conductora del programa utiliza parte de sus intervenciones en la conversación social para o bien indicar la firma o diseñador responsable de su vestuario o para introducir enlaces a su blog personal donde describe los estilismos utilizados; estas marcas y diseñadores, en cambio, no aprovechan este momento de notoriedad y no participan en la acción social.

Resultados audiencia social: Según los datos de Global in Media, los comentarios generados por este programa en las tres entregas analizadas alcanzan una

DOI: ri14.v13i2.822 | ISSN: 1697-8293 | Año 2015 Volumen 13 Nº 2 | ICONO14 
media de 40.181 (el día de mayor impacto fue el 25 de febrero, con 46.289 comentarios registrados). El número de usuarios únicos oscila entre los 13.313 del primer día y los 15.747 del tercero, registrándose un decrecimiento importante el segundo día de análisis (11.462). El minuto de oro se registra entre las 23:03 y las 23:22 horas, acumulando una media de 608 comentarios; podemos indicar que el último día de análisis se alcanzó un pico de 754 comentarios por minuto, logrando este espacio ser el contenido con más volumen de comentarios por minuto del día. Los sentimientos positivos y negativos se igualan en un $50 \%$ y la audiencia social masculina es ligeramente superior ( $54 \%$ de hombres frente a un $46 \%$ de mujeres).

¿Quién quiere casarse con mi hijo? ha logrado en febrero ser el segundo contenido televisivo más comentado en su franja de emisión. En cambio, si medimos la audiencia tradicional, el programa ocupa normalmente la tercera posición. El share medio alcanzado en febrero es del $12 \%$.

\subsection{Puesta en común}

Tras estudiar la estrategia de cada programa, a continuación, se ofrece una tabla comparativa de los principales aspectos analizados:

\begin{tabular}{|c|c|c|c|}
\hline \multicolumn{4}{|c|}{ INTERACCIÓN DEL PROGRAMA } \\
\hline $\begin{array}{c}\text { Las cuentas oficiales de Twitter presentan } \\
\text { actividad durante la emisión }\end{array}$ & GH VIP + GH VIP DEBATE & QQCCMH & LSN \\
\hline \multicolumn{2}{|c|}{ Sí Sí Sí } \\
\hline $\begin{array}{c}\text { Utilización hashtags propios durante la } \\
\text { emisión }\end{array}$ & Sí & Sí & Sí \\
\hline $\begin{array}{c}\text { Se sobreimpresionan en pantalla } \\
\text { Se convierten en trending topic durante } \\
\text { la emisión }\end{array}$ & Sí Sí & Sí \\
\hline $\begin{array}{c}\text { Se utilizan para animar al público a parti- } \\
\text { cipar en la conversación social }\end{array}$ & Sí & Sí \\
\hline $\begin{array}{c}\text { La participación de la audiencia social se } \\
\text { refleja en el programa. }\end{array}$ & Sí & No & No \\
\hline
\end{tabular}

ICONO14 | Año 2015 Volumen 13 Nº 2 | ISSN: 1697-8293 | DOI: ri14.v13i2.822 


\begin{tabular}{|c|c|c|c|}
\hline \multicolumn{4}{|c|}{ INTERACCIÓN DEL USUARIO } \\
\hline $\begin{array}{c}\text { Generan hashtags propios durante la } \\
\text { emisión }\end{array}$ & Sí & Sí & No \\
\hline $\begin{array}{l}\text { Media de comentarios (programas anali- } \\
\text { zados) }\end{array}$ & 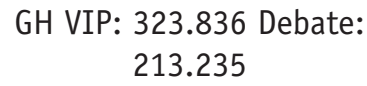 & 40.181 & 73.367 \\
\hline $\begin{array}{l}\text { Media de usuarios únicos (programas } \\
\text { analizados) }\end{array}$ & $\begin{array}{l}\text { GH VIP: } 65.000 \\
\text { Debate: } 38.500\end{array}$ & 14.530 & 18.616 \\
\hline
\end{tabular}

\begin{tabular}{|c|c|c|c|}
\multicolumn{2}{|c|}{ INTERACCIÓN PUBLICITARIA } & Sí & No \\
\hline $\begin{array}{c}\text { Se identifican patrocinadores } \\
\text { Patrocinador participa en la conversación } \\
\text { social }\end{array}$ & No & No & $\cdots$ \\
\hline $\begin{array}{c}\text { Patrocinador interactúa con las cuentas } \\
\text { de Twitter del programa }\end{array}$ & No & No & $\cdots$ \\
\hline $\begin{array}{c}\text { Se ofrecen promociones exclusivas duran- } \\
\text { te la emisión }\end{array}$ & No & No & $\cdots$ \\
\hline
\end{tabular}

\section{Discusión}

La audiencia social se ha convertido en una poderosa herramienta para incentivar la audiencia tradicional y mejorar la relación de los formatos televisivos con sus públicos. Siendo conscientes del volumen de audiencia social que se recoge a diario en los formatos televisivos españoles, podríamos afirmar que es un fenómeno asentado, con tendencia a incrementarse en los próximos años.

Esta comunicación bidireccional y vertical es conocida e implementada por todas las cadenas de televisión analizadas (Cuatro, Telecinco y La Sexta) al presentar cuentas oficiales de Twitter con actividad permanente y activa tanto para el medio como para los programas examinados en este trabajo.

Tomando como referencia los programas con mayor audiencia social del mes de enero, que presentaban continuidad para este análisis, se observa que los formatos que registran mayor número de comentarios corresponden a realitys shows (Gran Hermano VIP, El Debate Gran Hermano VIP y ¿Quién quiere casarse con mi hijo?), siendo La Sexta Noche el único formato con carácter informativo. Esta tendencia podía estar ligada a dos factores relevantes: la naturaleza emotiva de estos progra- 
mas, que generan mayor impacto emocional en la audiencia, y su emisión en horario prime time, que favorece el trasvase de audiencia tradicional a audiencia social.

En todos los casos analizados se ha detectado actividad relacionada con la audiencia social que presenta rasgos comunes: todos los formatos utilizan uno 0 varios hashtags oficiales que sobreimpresionan en pantalla, sus cuentas de Twitter aumentan su actividad antes, durante y después de la emisión del programa y comparten contenidos propios relacionados con el mismo.

No obstante, esta actividad suele ser arbitraria y no cuenta con una planificación real, por lo que representa una tímida aproximación a la generación real de estrategias que engloben a la audiencia social como parte intrínseca del programa. Muestra de ello es que en los casos analizados de programas con emisión en directo (Gran Hermano VIP, El Debate y La Sexta Noche) no existe ningún espacio específico dedicado a analizar las opiniones de la audiencia social, ni se anima a la misma a participar enviando preguntas o contenidos que contribuyan a enriquecer el formato. Esta carencia es aún más evidente en el que caso de La Sexta Noche que segmenta sus contenidos con hashtags específicos en los que sería aún más sencillo monitorizar las opiniones de la audiencia social.

A diferencia de estos formatos en directo, el programa ¿Quién quiere casarse con mi hijo? presenta una pseudo-estrategia de audiencia social algo más desarrollada en la que presentadora y concursantes participan de la conversación. Esta participación se incentiva desde el formato al sobreimpresionar la cuenta de Twitter de la presentadora, circunstancia que no se produce en el resto de los formatos analizados. A pesar de que la estrategia ha contribuido a aumentar la audiencia tradicional desde la audiencia social, ésta no ha mostrado una evolución desde la primera temporada.

Es necesario destacar que la participación de presentadores, tertulianos y colaboradores de los programas en la conversación social supone una inyección para la audiencia social que suele estar pendiente de sus comentarios y reacciones. Muchos de ellos, además, suelen contar con un gran número de seguidores, aumentando con sus comentarios de manera indirecta el flujo de la conversación.

ICONO14 | Año 2015 Volumen 13 Nº 2 | ISSN: 1697-8293 | DOI: ri14.v13i2.822 
En todos los casos, una de las grandes ventajas de la audiencia social es que aumenta el impacto del programa, alargando su vida e influencia. En algunos formatos, la conversación comienzaantes de la propia emisión y se mantiene horas, incluso días después del término de la misma. Esta circunstancia si es bien aprovechada puede servir al programa o la cadena para conocer mejor a su audiencia, mejorar su autopromoción, vender sus productos o incentivar el interés de cara a la siguiente emisión. Como ejemplo encontramos Gran Hermano VIP que utiliza de manera audaz su audiencia social y tradicional a través de su aplicación móvil. Gracias a este arrastre y a través de la inclusión de redes sociales como parte de la aplicación, la cadena genera registros para conocer a sus usuarios, aumenta la viralizacióny promoción de sus contenidos y potencia mediante alertas el interés y la visualización de sus futuros programas.

Una de las conclusiones más llamativas es que a pesar de que la audiencia social está consolidada en España y las cadenas de televisión hacen uso de la misma, los anunciantes van un paso por detrás en su planificación publicitaria. La audiencia social no se incluye en su planificación, ni se tiene en cuenta la posibilidad de realizar promociones o concursos que tengan, de algún modo, relación con el tipo de audiencia y contenido de la emisión. En consecuencia, los anunciantes desaprovechan sus propios recursos al pagar un alto precio por la compra de medios en prime time en los que podría potenciarse acciones de captación o de fidelización con la audiencia social. Asimismo, tampoco se tiene en cuenta la posibilidad de utilizar la segunda pantalla como vía para incentivar ventas, ni siquiera desde aplicaciones móviles ya creadas como es el caso de Gran Hermano.

Todos los hitos mencionados a lo largo de este trabajo suponen un punto de partida en las estrategias de las cadenas de televisión y anunciantes. Repensar la participación de la audiencia social en sus formatos y establecer vías de colaboración que engloben al público supondrá la diferenciación respecto a la competencia, abriendo nuevas vías de engagement y fidelización que contribuyan a mejorar los datos de audiencia tradicional, las ventas y la relación y el posicionamiento con los públicos. Ambos sectores precisan de nuevas metodologías de trabajo en las que el usuario se sienta escuchado y partícipe, gracias a la segmentación y al feedback inmediato y continuo. La audiencia social es el cambio hacia un modelo bidirec-

DOI: ri14.v13i2.822 | ISSN: 1697-8293 | Año 2015 Volumen 13 N² 2 | ICONO14 
236 | Marta Saavedra Llamas, Leticia Rodríguez Fernández y Gemma Baron Dulce

cional simétrico en el que medio-marca y consumidor establezcan lazos reales y permanentes más allá del impacto televisivo.

\section{Referencias}

AIMC (2014). Estudio General de Medios, Resumen General. Disponible en:http://www. aimc.es/-Datos-EGM-Resumen-General-.html[Consultado: 2014, 2 de mayo].

Arrojo, M.J. (2013). La televisión social. Nuevas oportunidades y nuevos retos para el sector audiovisual. I Congreso Internacional de Comunicación y Sociedad Digital. 17, 18 y 19 de abril de 2013, Universidad Internacional de La Rioja.

Castelló, A. (2013). El uso del hashtags en Twitter por parte de los programas de televisión españoles. I Congreso Internacional de Comunicación y Sociedad Digital. 17, 18 y 19 de abril de 2013, Universidad Internacional de La Rioja.

Cesar, P.; Geerts, D. (2011). Past, present, and future of social TV: A categorization. Consumer Communications and Networking Conference (CCNC), 2011 IEEE, pp. 347-351. doi: 10.1109/CCNC.2011.5766487.

Congosto, M.L., Deltell, L.; Claes, F. y Osteso, J.M. (2013): Análisis de la audiencia social por medio de Twitter. Caso de estudio: los premios Goya 2013, Icono 14, volumen 11 (2), pp. 53-82. doi: 10.7195/ri14.v11i2.577.

Echegaray, L.; Peñafiel, C. (2013). La utilización de las redes sociales como nuevas herramientas aplicadas al análisis de audiencias. Trípodos, Barcelona, p.33.

Gallego, F. (2012). La medición de la televisión social en España: concepto, evolución y posibilidades presentes y futuras. III Congreso Internacional Comunicación 3.0, Salamanca, 10 y 11 octubre de 2012, p.1.

Geerts, D.; De Grooff, D. (2009). Supporting the social uses of television: sociability heuristics for social TV. Proceedings of the SIGCHI conference on human factors in computing systems, ACM,pp. 595-604.doi: 10.1145/1518701.1518793.

González Neira, A.; Quintas, N. (2014). Twitter, la televisión y la audiencia social. ¿Por qué triunfa un espacio en la audiencia social?. Disponible en http://www. foro2014.com/wp-content/uploads/2014/02/31.-Gonz\%C3\%A1lez-Quintas. pdf. [Consultado: 2013, 29 de abril].

González Neira, A.; Quintas, N. (2015).A new challenge for advertising on mobile devices: social TV. Icono 14, volumen 13 (1), pp. 52-75. doi: http://dx.doi. org/10.7195/ri14.v13i1.755 Disponible en: http://www.icono14.net/ojs/

ICONO14 | Año 2015 Volumen 13 Nº 2 | ISSN: 1697-8293 | DOI: ri14.v13i2.822 
index.php/icono14/article/view/755[Consultado: 2015, 29 de abril]. IAB (2014). V Estudio Anual de Redes Sociales. Disponible en http://www.iabspain. net/wp-content/uploads/downloads/2014/04/V-Estudio-Anual-de-RedesSociales-versi\%C3\%B3n-reducida.pdf. [Consultado: 2014, 10 de mayo].

López de Ayala, P. (2014). Twitter aumenta la audiencia de la TV: el 67\% de los usuarios ve un programa tras leer comentarios en la red social. Marketing Directo. Disponible en http://www.marketingdirecto.com/actualidad/social-mediamarketing/twitter-aumenta-la-audiencia-de-la-tv-el-67-de-los-usuarios-veun-programa-tras-leer-comentarios-en-la-red-social/. [Consultado: 2015, 3 de enero].

Marcos, N. (2014). La televisión y Twitter consolidan su relación. El País. Disponible en: http://cultura.elpais.com/cultura/2014/12/04/television/ 1417689029_704368.html. [Consultado: 2014, 4 de diciembre].

Martín, E; Sánchez, C. (2014). Audiencia Social: ¿Tú también, publicidad?, Tuitele. Moreno, M. (2015). Twitter prueba timelines especificos para programas de TV. Trece Bits. Disponible en http://www.trecebits.com/2015/03/13/twitter-pruebatimelines-especificos-para-programas-de-tv/. [Consultado: 2015, 14de marzo]. Muñoz, R. (2015). Las marcas multiplicaron por 5 su actividad en redes sociales en 2014. Mediatics. Disponible en: http://www.media-tics.com/noticia/5382/ Internet/Las-marcas-multiplicaron-por-5-su-actividad-en-redes-socialesen-2014.html. [Consultado: 2015, 9de marzo].

Nielsen (2013).The future of TV is social. Disponible en: http://www.nielsen.com/ us/en/newswire/2013/the-future-of-tv-is-social.html. [Consultado: 2013, 29 de marzo].

Orihuela, J. L. (2011). Mundo Twitter.Una guía para comprender y dominar la plataforma que cambió la red. Barcelona: Alienta Editorial.

Rodríguez Breijo, V.; Pestano, J.M. (2013). El monólogo Twitter: características de la participación de la teleaudiencia en los programas de opinión. Actas $\mathrm{V}$ Congreso Internacional Latina de Comunicación Social - V CILCS, Universidad de La Laguna, diciembre de 2013.

Saavedra, M.; Rodríguez Fernández, L.; Perlado, M. (2015) Audiencia social. XVI Foro de Investigación en Comunicación. Universidad de Extremadura, febrero de 2015.

DOI: ri14.v13i2.822 | ISSN: 1697-8293 | Año 2015 Volumen 13 N² 2 | ICONO14 